\title{
artículos
}

\section{Las raíces de un estruendo: el legado de Platón en la génesis del pensamiento dialéctico hegeliano}

The Roots of a Rumble: Plato's Legacy in the Genesis of Hegelian Dialectical Thought 
Resumen: A pesar de la importancia ampliamente conocida que Hegel siempre dio a pensadores como Aristóteles o Heráclito, otras filosofías clásicas, como la de Platón, han tenido un papel esencial a la hora de inspirar y fundamentar las bases de la filosofía hegeliana. Por ello, en este artículo, a partir de la interpretación que hizo Hegel de la filosofía platónica en los periodos que van desde su estancia en el Tübinger Stift a la etapa de elaboración de la Fenomenología del Espíritu (1788-1806), estudiaremos las muy importantes contribuciones de la dialéctica platónica a la génesis de la dialéctica hegeliana, además de los paralelismos y distancias entre ambos modelos de dialéctica, intentando destacar su influencia en los desarrollos filosóficos posteriores. Y es que, si como bien dice Hegel en la Fenomenología, la tarea de la Modernidad no "trata tanto de purificar al individuo de lo sensible inmediato y de convertirlo en sustancia pensada y pensante, sino más bien de lo contrario, es decir, de realizar y animar espiritualmente lo universal», hoy, en el momento de la postmodernidad en el que los universales se derrumban, es más importante que nunca volver a hacer patentes las raíces que, Ilegado un momento, comenzaron a hacerlos temblar.

Palabras clave: Dialéctica, escepticismo, neoplatonismo, isostheneia, unidad, Modernidad.

Abstract: Despite the well-known role that Hegel ascribed to Aristotle's and Heraclites' philosophies, other classic philosophies, as Plato's philosophy, had an essential role in the inspiration over foundations of Hegel's positions. For this reason, in this work we are going to study the contributions of Plato's dialetics to Hegel's dialectics' development; ranging from Hegel's interpretation of Plato's dialetics since his stay at the Tubinger Stift to the elaboration of Phenomenology of Spirit (1788-1806). We are also going to study the contributions of Plato's dialectics to Hegel's dialectic's development. Parallels and differences between both models will be analysed as well as their influence on later philosophical developments. According to Hegel's Phenomenology, the mission of Modernity is not to purify individuals from the immediate sensitive but instead to develop and animate spiritually universals. We will try to show that nowadays, in times when the universals fall, it is essential to reflect on the roots that, in other times, made them tremble.

Keywords: Dialectics, skepticism, neoplatonism, isostheneia, unity, Modernity. 


\section{Introducción}

Como bien nota el investigador chileno Sergio Montecinos, la dialéctica les un modo de conocimiento que, en la Modernidad, de entrada, solo puede generar desconfianza ${ }^{1}$ ¿ ¿Cómo es posible confiar en una disciplina que se basa en buscar contradicciones y en la que nada sólido parece sostenerse? ¿Por qué volver a preocuparse por aquella «lógica de la ilusión», como la calificó Kant, si las certezas que creíamos firmes se disuelven en ella como la sal se disuelve en el mar? ¿`Y no hay riesgo de que, en la dialéctica, con todo lo sólido, perdamos también a la verdad? Visto así, este modo de conocimiento no parece muy atractivo para nuestra época moderna, tributaria de los modelos de demostración racional basados en la exigencia de apodicticidad típica de autores como Descartes o Aristóteles. Sin embargo, pocos pensamientos han generado conmociones tan grandes en la forma de enfrentarse a la Modernidad como lo ha hecho el pensamiento dialéctico de la mano de su gran rehabilitador moderno: G.W.F. Hegel. ¿Qué tiene la dialéctica para que Hegel volviera su mirada a aquel pensamiento de otro tiempo?

Una parte importante de la respuesta a esta pregunta parece residir en Platón y, concretamente, en la profunda lectura que Hegel hará del ateniense en sus primeros años hasta la época de Jena y la publicación de la Fenomenología. Y es que fue en Platón -o, al menos, en su lectura de él- donde Hegel reconoció la manifestación más elevada de este pensamiento dialéctico griego ${ }^{2}$, encontrando en él gran parte de las razones por las que comenzó a valorar el papel que lo dialéctico podría tener en la Modernidad. Así, esta falta de solidez de la dialéctica antigua leída por Hegel no solo no fue un defecto para

1 MONTECINOS, S., "Conexiones metodológicas entre las filosofías de Platón y Hegel: la lectura platónica de la dialéctica hegeliana», Bajo Palabra, Universidad Autónoma de Madrid, Madrid, Época II, n. 4, año 2009, p. 108.

2 HEGEL, G.W. F., Fenomenología del Espíritu, Abada, Madrid, 2010, p. 135 y HEGEL, G. W. F., La Relación del Escepticismo con la Filosofía, Biblioteca Nueva, Madrid, 2013, pp. 65-66. 
él, sino que, como notará en sus Lecciones sobre Historia de la Filosofía a propósito de Zenón, le hará asumir que la dialéctica es «ella misma movimiento», aportando a Hegel la vía para poder llevar a cabo al menos dos de las grandes tareas de la Modernidad: por un lado, «realizar y animar espiritualmente lo universal» ${ }^{3}$, recuperando la vida dormida en los petrificados conceptos de su época y fluidificando de nuevo el pensamiento, y por el otro, expandir los límites de nuestra consideración de lo real más allá del limitado y mecanicista campo del entendimiento ${ }^{4}$.

La interpretación que hizo Hegel del pensamiento dialéctico platónico no fue una mera apropiación pasiva: los planteamientos de Hegel, como el propio filósofo observó, tomaron, debido a las distancias propias de la época moderna y la antigua, caminos distintos a los de la dialéctica platónica, y su retrato de Platón llegó, en ciertos puntos, a violentar la propia letra platónica. Sin embargo, estos desarrollos originales de Hegel no se podrían entender sin el muy productivo diálogo crítico con la tradición platónica que tuvo el suabo en sus etapas de juventud, tomando de él un concepto propio de exposición de la verdad y teniendo lo platónico ${ }^{5}$ un papel fundamental en el proceso de gestación de las primeras configuraciones dialécticas de su pensamiento. Por ello, en este artículo intentaremos remontar al origen de esta nueva navegación dialéctica de la Modernidad que hizo Hegel, intentando aislar las líneas de influencia del pensamiento platónico en el pensamiento temprano de Hegel. Y así, nos centraremos fundamentalmente en el periodo de tiempo que va desde la etapa de formación superior de Hegel en el Tübinger Stift-1788 a 1792- a su estancia en Jena -1801-1806-, intentando ver qué influencia ejerció lo platónico en distintas etapas de la producción filosófica juvenil de Hegel -especialmente Tubinga, Frankfurt y Jena- y la importancia que aún hoy sigue teniendo esta fecunda lectura de Platón que realizó el joven Hegel.

3 HEGEL, G. W. F., Fenomenología del Espíritu, op. cit., p. 93.

4 MONTECINOS, S., "Conexiones metodológicas entre las filosofías de Platón y Hegel: la lectura platónica de la dialéctica hegeliana». Bajo Palabra. op. cit., p. 124.

5 Como bien nos hacía notar uno de los revisores de este artículo, en estas líneas es importante evitar una indistinción acrítica entre Platón, el platonismo y la interpretación hegeliana de Platón bajo el signo de «lo platónico». Por ello, si bien en algunos puntos usaremos de forma equivalente dichos términos, es esencial observar la señalada distancia entre los escritos del propio Platón, las tradiciones (plurales) de interpretación de Platón encuadradas en el platonismo (o, quizá más propiamente, los platonismos), y el Platón leído y reconstruido por nuestro filósofo suabo, tres dimensiones muchas veces indistinguidas en Hegel. En este texto, debido a nuestra focalización temática en el desarrollo de la filosofía hegeliana, en algunos puntos no profundizaremos en las posibles líneas de interpretación de las diferencias y tensiones entre las tres realidades y daremos una imagen de Platón cercana a la que el propio Hegel tenía, influenciada tanto por su lectura como por las tradiciones de interpretación de Platón desde las que leyó al ateniense. Sin embargo, como señalamos en diversas partes del texto posteriormente, tener en cuenta estas diferencias es fundamental para entender la originalidad de Hegel frente a la dialéctica antigua y la violencia de alguno de los aspectos de su interpretación de la filosofía platónica. 


\section{Por los senderos del «ideal juvenil»: La recepción temprana de Platón en el pensamiento de Hegel en Tubinga}

Para rastrear el inicio de la lectura hegeliana de la filosofía platónica tenemos que remontarnos a su etapa de formación superior en el Tübinger Stift, de 1788 a $1792^{6}$, donde compartió educación con los que fueron sus amigos, compañeros de cuarto y profundas fuentes de influencia: el futuro filósofo Friedrich Schelling y el poeta Friedrich Hölderlin. Fue durante esos años -y especialmente durante el periodo de verano de 1790, mientras asistía a las clases de profesor Flatt- donde parece que inició, junto con Hölderlin, una gran parte de esas primeras lecturas de Platón ${ }^{7}$, que continuaron durante toda la década siguiente $^{8}$. Y fue justo entonces cuando lo platónico comenzó a sentirse en la filosofía hegeliana, aunque aún de forma muy temprana e incipiente.

Como bien nos muestran casi todas las fuentes y sus textos directos ${ }^{9}$, las preocupaciones de Hegel en estos primeros años de la década de 1790

6 DUQUE, F., Historia de la filosofía moderna. La era de la crítica, Akal, Madrid, 1998, p. 324 y HARRIS, H. S., Hegel's Development: Towards the Sunlight, Oxford University Press, Oxford, 1971, p. 98.

7 A este respecto ha habido comentarios en obras recientes (véase SURBER, J. O., «Hegel's Plato: A new departure», en KIM, A., Brill's Companion to German Platonism, Brill, Leiden, 2019, p. 132) sobre un supuesto conocimiento deficiente de Hegel de lenguas clásicas debido a la formación en el Stift y que le hubiera impedido leer de forma directa a Platón en su juventud, dependiendo de traducciones informales al alemán que, si bien no empezaron a editarse en Alemania hasta 1804 de la mano de Schegel y Scheleimeier, sí circulaban en la época. Sin embargo, ello parece poco acorde con la realidad si se tiene en cuenta que ya aprendió latín a muy temprana edad de la mano de su madre (HARRIS, H.S., Hegel's Development: Toward the Sunlight, op. cit., p. 2), siendo su dotación para ello uno de los motivos que impulsaron a su familia a favorecer su desarrollo académico. Además del latín, todo apunta a que tenía un conocimiento elevado también de griego en su etapa de educación elemental. Es poco plausible que no pudiera, por tanto, leer directamente ediciones como las neoplatónicas de Ficino -que estaban disponibles en la época, y a las que, de hecho, otros contemporáneos como Hölderlin tuvieron acceso - u otras ediciones bilingües latín-griego de los diálogos (Véase BARRIOS, M., "La incidencia de la imagen de Grecia en la obra temprana de Hölderlin», Contrastes: revista internacional de filosofía, XXII-n.' 2, 2017, p. 127).

8 En esta lectura tuvo gran importancia la influencia de su profesor Conz (BARRIOS, M., «La incidencia de la imagen de Grecia en la obra temprana de Hölderlin», op. cit., p. 125) y se realizó probablemente a partir de las ediciones frankfurtianas de los diálogos de 1602, que contendrían la edición bilingüe griego-latín realizadas por Marsilio Ficino en la Academia Florentina. Además, sabemos que Hölderlin, según los registros de la biblioteca del Stift, leyó varios diálogos a partir de la edición comentada por el florentino. También estaría disponible en el espacio cultural alemán a partir de 1781 la edición bipontina. El hecho de que estas primeras lecturas se realizaran a partir de textos neoplatónicos tendrá una importancia fundamental en la recepción que los autores del idealismo alemán realizaron de la filosofía platónica.

9 Es importante tener en cuenta aquí que Hegel, en estas etapas que van desde su estancia en el Stift hasta su época de Frankfurt, no publicó nada, exceptuando un panfleto político sobre la dominación por parte de Berna de los pueblos del Vaud en su etapa como preceptor en dicha ciudad (VIELLARD-BARON, J.-L., Platonisme et interprétation de Platon à l'epoque modern, 
estuvieron marcadas por dos hechos que fueron fundamentales para entender el ambiente intelectual, social y político que los jóvenes estudiantes del Stift vivieron: por un lado, la publicación en 1781 de la Crítica de la Razón Pura (KrV) por parte de Immanuel Kant, y por el otro, el estallido de la Revolución Francesa frente al gobierno absolutista de Luis XVI en 1789. Y no era para menos: ambos hechos, a la par que ascendía una nueva clase social pujante, la burguesía, parecían implicar una profunda ruptura con los fundamentos y el modelo de sociedad anterior, anunciando un mundo nuevo. Si la sociedad del Antiguo Régimen se había basado durante siglos en la autoridad de lo externo - un Dios trascendente, un rey absoluto, un objeto de conocimiento- para la construcción de sus distintos ámbitos políticos, religiosos o intelectuales, el impulso de ambas revoluciones rompía con esta exterioridad, poniendo el énfasis en el sujeto libre y actuante. Y así, mientras la revolución kantiana proponía una revolución copernicana que dejara de centrarse en los objetos de conocimiento para fijar su mirada en el sujeto cognoscente y las condiciones subjetivas del conocimiento $^{10}$, la Revolución Francesa consumaba el papel activo de los individuos en la sociedad, que pasaban de ser súbditos a ser ciudadanos emancipados de la minoría de edad a la que habían estado sometidos ${ }^{11}$.

En este torbellino de fuertes convulsiones políticas, filosóficas y sociales, Hegel estuvo expuesto a diversas y complejas polémicas que, además de ser importantes para el desarrollo de su pensamiento, fueron esenciales en la ruptura de los esquemas de la sociedad prerrevolucionaria y la construcción del

Vrin, Paris, 1998, p. 155). Por ello, todos los textos que produjo en estas épocas fueron textos que nunca publicó en vida, aunque algunos, como por ejemplo «El espíritu del cristianismo», ya eran textos de un volumen considerable y recogían de forma clara sus influencias filosóficas. En la publicación de estos textos de juventud destaca la edición que hizo Nohl en 1907 en el compendio Escritos teológicos de juventud, y en castellano, además de la traducción por parte de María del Carmen Paredes del «Fragmento de Tubinga» («G.W.F. Hegel: El fragmento de Tubinga», Revista de Filosofía, Editorial Complutense, Madrid, Época III, Vol. VII, 1994, pp. 139-176) o de Leben Jesu de Santiago González Noriega (HEGEL, G. W. F., Historia de Jesús, Taurus, Madrid, 1981), tenemos la traducción de José María Ripalda de los textos más representativos entre 1795 y 1800, recogidos en el volumen Escritos de Juventud (HEGEL, G. W. F., Escritos de Juventud, Fondo de Cultura Económica, Ciudad de México, 1978).

10 KANT, I., Crítica de la Razón Pura, Taurus, Barcelona, 2013, pp. 20-21.

11 KANT, I., «Qué es la Ilustración», Foro de la Educación, 11, p. 249. En esta etapa de Tubinga es importante tener en cuenta que el joven Hegel, si bien recibió entusiastamente a la Revolución Francesa (aunque desde una perspectiva ciertamente girondina), no tuvo el mismo entusiasmo por la filosofía kantiana. Hegel leyó profundamente a Kant en el Seminario (empezando por la Crítica de la Razón Pura en el segundo curso y siguiendo por la Crítica de la Razón práctica (HARRIS, H.S., Hegel's Development: Towards the Sunlight. op. cit., pp. 73, 83 y 89), pero no participó en los clubs de lectura de Kant en donde fueron acogidos Schelling y Hölderlin. También ha de tenerse en cuenta que, ya en su etapa de Stuttgart, Hegel había sido influenciado por su profesor, el profesor Abel, contra dicha filosofía. Por ello, si bien la profunda influencia de Kant se puede ver en todos los textos de esta época, Ilegando a su máxima expresión en su Leben Jesu de su posterior etapa de Berna, Hegel tuvo una cierta distancia crítica con el kantismo desde sus primeras lecturas. 
pensamiento en el futuro mundo burgués. Pero fue concretamente en la lectura de una de ellas, la polémica sobre el supuesto spinozismo del estandarte de la Ilustración alemana, Gottfried Ephraim Lessing, donde, de acuerdo con algunos autores $^{12}$, podemos localizar los primeros momentos en los que ciertos planteamientos provenientes de la filosofía platónica comenzaron a jugar un papel en el pensamiento de Hegel. Y es que la lectura conjunta de esta polémica y de ciertas obras de Platón -que realizó simultáneamente a partir de 1790- fue lo que parece que empezó a moldear ciertas concepciones rupturistas de la divinidad en el pensador suabo, que fueron importantes en sus desarrollos filosóficos posteriores.

¿Por qué tuvo importancia para Hegel esta polémica sobre el spinozismo de Lessing, asociada a su lectura de Platón, y en qué sentido implicó un cambio en sus concepciones de la divinidad? Para entenderlo, además de notar la profunda significación que tenía para el Hegel de Tubinga una figura como Lessing, protagonista de la Ilustración Alemana y de muchas de las influencias a las que estuvo expuesto en su muy cuidada educación secundaria, es esencial entender la gravedad que implicaba ser acusado de spinozista en aquellos años de finales del siglo XVIII. El spinozismo se había convertido en una especie de anatema equiparable al ateísmo y a un tipo de racionalismo que caía en un determinismo fatalista, ya que esta doctrina rompía con las concepciones del Dios personal y trascendente, presentes en los dogmas cristianos, y defendía una concepción de Dios inmanente ${ }^{13}$. Por ello, esta polémica, que estalló cuando F.H. Jacobi le mandó una carta al biógrafo y amigo de Lessing, Moses Mendelsohn, relatándole la supuesta confesión que le realizó Lessing en su lecho de muerte sobre su spinozismo, implicaba un ataque frontal a las raíces de la Ilustración. Decir que alguien de la relevancia de Lessing en el movimiento ilustrado alemán era spinozista en aquel momento era equiparable a asumir que la Ilustración tenía en su base el germen del ateísmo ${ }^{14}$.

12 HARRIS, H.S., Hegel's Development: Towards the Sunlight. op. cit., pp. 98 y ss.

13 Incluso desde el momento de su surgimiento, la filosofía de Spinoza había sido condenada al ostracismo y combatida por diversos pensadores debido a su ruptura con múltiples dogmas religiosos y políticos. Sin embargo, es interesante tener en cuenta que la crítica no fue unánime. El apoyo a Spinoza fue representado por autores como F. W. Stosch, T. L. Lau o J. C. Edelmann, pero, además de ser minoritarios, fueron duramente reprimidos a principios del XVIII por parte de autoridades religiosas y civiles. Ser spinozista era peligroso en el Antiguo Régimen, y el renacimiento del spinozismo tras la polémica sobre el supuesto spinozismo de Lessing será una clara demostración de que algo estaba cambiando en las sociedades europeas en la época de la Revolución. Para un análisis detallado, véase el excelente SOLÉ, M. J., El ocaso de la llustración: La polémica del spinozismo. Universidad Nacional de Quilmes, Bernal, 2012, especialmente el estudio introductorio.

14 En ese sentido, es importante notar que estas concepciones monistas fueron asociadas por muchos autores con un mecanicismo y una cadena de causas eficientes. Si Dios es inmanente, se podría entender que su papel activo como causa eficiente en la naturaleza santificaría todo el devenir de la naturaleza, eliminando todo sentido a la diferencia entre bien y mal. 
Y así, Jacobi creía mostrar la incompatibilidad entre el proyecto racional de la Ilustración y los dogmas de fe que fundamentaban el orden religioso, político y moral del Antiguo Régimen.

Sin embargo, esta polémica tuvo una consecuencia paradójica: más que hacer, como quería Jacobi, que la sociedad volviera a ese Dios personal y trascendente, tan afín al modelo del Antiguo Régimen, lo que hizo fue, por un lado, popularizar el spinozismo, con su concepción inmanente de la divinidad, y, por el otro, favorecer una reformulación de los planteamientos ilustrados de la mano del criticismo kantiano, siendo más bien estos planteamientos de Jacobi el canto del cisne de la dominación de muchos dogmas religiosos en el ámbito intelectual. En ese sentido, los jóvenes estudiantes del Stift fueron claramente influenciados por estas consecuencias paradójicas de la polémica. Y por ello, Hegel integró, como sus amigos Hölderlin y Schelling, estas concepciones de divinidad inmanente propias del spinozismo popularizado de la época, con un eco que nos recuerda a los planteamientos protorrománticos del Sturm und Drang y su panteísmo. Sin embargo, frente a Schelling y autores ya consagrados como Herder, que rechazaban una concepción de la divinidad personal ${ }^{15}$, Hölderlin y, especialmente, Hegel, intentaron conciliar esta inmanencia spinoziana con la idea de Dios como un arquitecto del cosmos a la manera leibniziana e ilustrada. Y fue en ese punto donde encontraron en Platón un aliado en la construcción de una idea de divinidad que recogía ambos ámbitos de lo divino.

Desde una lectura fuertemente neoplatónica de Platón, acorde, como ya hemos comentado ${ }^{16}$, con las ediciones de Platón dominantes en la época y que presentaban a un Platón místico y muy centrado en un entusiasmo que lo relacionaba con la divinidad, Hegel y Hölderlin encontraron en Platón una visión de la divinidad como alma del mundo [Seele des Weltalls] que, a su parecer, permitía conciliar ambos caracteres. Por un lado, entendía lo divino como una divinidad inmanente, y que, en tanto que inmanente, era el fundamento del devenir de la realidad. Pero, por otro lado, también les permitía entender a esta divinidad desde esa perspectiva leibniziana del «arquitecto del cosmos», al asumir que estaba implícita en ella un plan racional de diseño del cosmos, plan que se podría ver en las regularidades tanto de la astronomía como en las de los cuerpos organizados. Y aunque estas nuevas concepciones de lo divino eran aún embrionarias y no tuvieron la importancia en esta época para Hegel que posteriormente tomaron, dieron tanto a Hegel como a Hölderlin un germen intelectual para la superación de las concepciones externas de la religión y la moralidad presentes en Kant. Así, frente a la concepción del mandato

15 Es interesante notar en este punto la distancia que ya existía entre el desarrollo filosófico de Schelling y el de Hegel desde estas épocas tan tempranas, y que posteriormente se solidificó en las críticas de la Fenomenología a Schelling, lo que les hizo romper la amistad.

16 Cfr. supra nota 7. 
moral como algo externo a nuestra sensibilidad cuya ley se nos impone, Hegel -junto con Hölderlin- comenzó a ver en esta concepción del alma del mundo una potencia fundamentadora de la realidad inserta en el propio devenir de la realidad. Si el proyecto de la revolución implicaba el derrumbamiento de autoridades externas que imponían su ley desde fuera, estas concepciones inmanentes de la divinidad supondrán poner el énfasis en las leyes insertas en el darse de la realidad sin la necesidad de apelar a elementos exteriores como de los que aún era dependiente $\mathrm{Kant}^{17}$. Sin embargo, en este camino de superación de los dogmas dominantes en la época y del kantismo no fue Hegel el que llevó la iniciativa, sino Hölderlin. Habrá que esperar varios años, hasta el traslado de Hegel a Frankfurt bajo la protección del poeta, para ver cómo Hegel desarrolló estas tendencias incipientes. Y es que fue allí donde elaboró su propia vía de superación de Kant, apoyándose fuertemente en el platonismo y, sobre todo, en la influencia de su buen amigo.

\section{Entre el amor y el escepticismo: la influencia de Hölderlin y Platón en los nuevos caminos de Hegel en Frankfurt}

Hegel llegó a Frankfurt en 1796. Desde su salida de Tubinga Hegel había estado trabajando de preceptor en Berna, y gracias a otro trabajo de preceptor que le consiguió Hölderlin en la ciudad del Meno, el suabo pudo romper el aislamiento que había sufrido desde el fin de sus estudios, integrándose en el círculo intelectual del poeta. Fue en este marco cuando lo platónico empezó a entrar con toda su fuerza en el pensamiento hegeliano, pudiéndose ver en esta etapa los primeros rasgos firmes del Hegel con el que nos encontraremos

17 Ni Hegel ni Hölderlin harán una crítica explícita a Kant en estas primeras etapas; sin embargo, comienzan a estar presentes en sus textos tanto la nueva concepción de lo divino como la idea de la hermandad de todo lo viviente, elementos en los que lo platónico parece estar jugando un papel central y que ya sugieren las vías de superación de lo kantiano que Hegel realizará más tarde. En ese sentido, si bien Hegel ensayará en su etapa de Berna proyectos religiosos basados en las concepciones kantianas como el presente en Leben Jesu, el suabo mostrará en otras construcciones de su Volksreligion cómo es necesario, para llevar a cabo el Reino de Dios en la Tierra a la luz de la Revolución, una concepción fuertemente experiencial de la religión, de raíz griega, donde deber y querer estuvieran conciliados, donde la moralidad se diera en los instintos -en un concepto cercano a la noción de moralidad de los instintos de Hölderlin en Sobre la ley de la libertad (BARRIOS, M., "La incidencia de la imagen de Grecia en la obra temprana de Hölderlin», op. cit., p. 125) - y no se dependiera de una moralidad fría y externa, ajena al devenir de nuestra propia realidad. Así, el hegeliano «Reino de Dios» no será entendido como una dictadura de un Dios trascendente que impone su ley desde fuera del mundo, de ecos despóticos, sino, a partir de ahora, como un desarrollo de las leyes inmanentes divinas ya presentes en el darse de lo real, en una clara muestra de la fuerte co-dependencia de sus planteamientos políticos insertos en estos trabajos religiosos respecto a sus consideraciones místicas y platónicas, que nota Viellard-Baron (VIELLARD-BARON, J.-L., Platonisme et interprétation de Platon à l'époque moderne, op. cit., 155-158). 
en Jena. Pero su vía de entrada no fue una vía solipsista de lectura de lo platónico, ni una ocurrencia afortunada del genio, sino que en ella tuvo un papel fundamental la influencia de su protector en esta etapa, fiel amigo y ya afamado poeta, Friedrich Hölderlin.

¿En qué estaba trabajando Hölderlin en la época en la que nuestro joven preceptor decidió mudarse a la bulliciosa Frankfurt? Junto con la llamada «Liga de los espíritus», un círculo intelectual entre los que destacan el diplomático von Sinclair y Zwilling ${ }^{18}$, Hölderlin estaba intentado desarrollar una filosofía de la unificación (Vereinigungsphilosophie), a caballo entre lo filosófico y lo poético, en la que, profundizando en las concepciones platónicas de la divinidad que comenzó a desarrollar en Tubinga, pudiera pensar la esfera propia de ese principio unificador que constituía el mundo. Y en ese sentido, Hölderlin integró, como muy bien nota Dieter Heinrich en su fundamental Hegely Hölderlin ${ }^{19}$, esas corrientes minoritarias y paralelas al pensamiento dominante que había representado el platonismo y el neoplatonismo en aquellos años.

¿Cómo era posible pensar esta esfera suprema y conciliada de lo real? ¿Era suficiente el entusiasmo (neo)platónico, que llevaba a mundos supracelestes ${ }^{20}$, pero no se enfrentaba a las oposiciones, como las que existían entre deber y voluntad, en las que habían caído filosofías como la kantiana? Hölderlin, en una línea cercana a lo que había intentado Schiller ${ }^{21}$, exploró el camino para conciliar las oposiciones del kantismo en un modelo cercano al platónico, pero no fue hasta la lectura de la filosofía de Fichte el momento en el que Hölderlin pudo teorizar una vía de superación al kantismo, al darle un camino para pensar la oposición como algo fundamental en el darse de lo real, a partir de la contraposición del Yo y No-Yo, con un fundamento unitario subyacente a la contraposición, como era la incondicionalidad de la conciencia para Fichte ${ }^{22}$.

Hölderlin asumió esta estructura básica de Fichte, pero discrepando en un elemento fundamental: ¿podía ser la incondicionalidad de la conciencia ese fundamento unitario a las contraposiciones? Para Hölderlin, como de forma clara criticó en su pequeño ensayo fuicio y Ser, escrito en las solapas de la obra cumbre de Fichte Grundlage der gesammten Wissenschaftslehre, ese fundamento de unidad no puede residir en una «yoidad» ${ }^{23}$. Así, con Hölderlin, «este ser no debe ser confundido con la identidad. Cuando digo «yo soy yo», el sujeto (yo) y el objeto (yo) no están unidos de tal manera que ninguna separación pueda

18 MONTECINOS, S., «Máscaras del escepticismo en la filosofía hegeliana», Estudios de Filosofía, Universidad de Antioquía, Antioquía, n. 60, 2019, p. 114.

19 HEINRICH, D., «Hegel y Hölderlin», Diálogos, Universidad de Puerto Rico, San Juan, n. 20, p. 52.

20 Ibid., p. 58.

21 Ibid., pp. 56-57.

22 Ibid., p. 58.

23 Ibid., p. 59. 
ser efectuada sin dañar la esencia de aquello que debe ser separado: al contrario, el yo sólo es posible por medio de esta separación del Yo respecto al Yo» ${ }^{24}$. Hablar de un yo implica necesariamente una autoconciencia, y para el darse de una autoconciencia es esencial una separación en el entendimiento que fije al yo como objeto contrapuesto, implica una posterioridad a las oposiciones que pretendía unificar. Por ello, el Yo no expresaría una unificación entre sujeto y objeto, sino que es posterior al darse de la oposición, que es intrínseca a los juicios del entendimiento y a la racionalidad reflexiva.

Los juicios del entendimiento serían para él, a partir de una etimología irreal, una partición originaria (urteil - Ur-Theilung) en la que siempre estaría esta escisión. Y es que, en tanto que facultad de fijación, el entendimiento generaría y fijaría oposiciones que determinarían la estructura de la proposición del entendimiento como una proposición construida a partir de elementos en oposición, de un sujeto, un hipokeimenon aristotélico, subyacente, y un predicado, un objeto, accidental y externamente unido al sujeto. Así, es en esa partición originaria, como bien nota Barrios ${ }^{25}$, donde Hölderlin estaba señalando una insuficiencia que Hegel en Frankfurt asumirá también (y ya no le abandonará $^{26}$ ): la insuficiencia de la proposición del entendimiento para expresar toda la riqueza de la vida y de la realidad al estar estructurada en oposiciones rígidas que no se podían reconciliar. Por ello, la clave es remontarse al fundamento unitario, que tanto Hölderlin como Hegel identificaron en estos años con el amor, entendido a la manera platónica ${ }^{27}$.

24 HÖLDERLIN, F., Ensayos, Peralta, Madrid, 1976, p. 26 y BARRIOS, M., «La incidencia de la imagen de Grecia en la obra temprana de Hölderlin», op. cit., p. 129.

25 BARRIOS, M., «Hegel: Una interpretación del platonismo», Anales del seminario de metafísica, Universidad Complutense de Madrid, Madrid, n. 29, 1993, p. 143.

26 MONTECINOS, S., La asunción de la reflexión finita en la filosofía de G. W. F. Hegel, UAM, Madrid, 2015, p. 76.

27 Frente a las continuidades que en este apartado estamos trazando entre Hölderlin y Hegel, hay otras interpretaciones, fuertemente tributarias de la lectura heideggeriana de Hölderlin, que ponen énfasis en las distancias de Hölderlin con los próceres del idealismo alemán: Hegel y Schelling. Para consultar sus principales textos en lengua castellana, recomendamos De Kant a Hölderlin, de Felipe Martínez Marzoa (MARTíNEZ MARZOA, F., De Kant a Hölderlin, La Oficina, Madrid, 2018) y el muy reciente estudio previo a Cartas Filosóficas de Hölderlin de Arturo Leyte titulado «El filósofo que no quería serlo» (CORTÉS, H. y LEYTE, A. (eds.), Cartas Filosóficas de Hölderlin, La Oficina, Madrid, 2020). Sin embargo, es importante señalar que las líneas de interpretación de Hölderlin favorecidas por Martin Heidegger no generan unanimidad en el ámbito académico, habiendo desde épocas muy tempranas líneas de resistencia a esa interpretación, como la representada por Theodor W. Adorno y su provocativa conferencia en la Hölderlin-Gesellschaft, recogida su transcripción en el volumen 11 de sus obras completas (ADORNO, T. W., Notas sobre literatura, Obra completa, 11, Ediciones Akal, Madrid, 2003). Dichos planteamientos adornianos han sido recogidos recientemente en castellano en volúmenes como CARRASCO CONDE, A., MACOR, L. A., ROCCO, V. (eds.), Hegel y Hölderlin: una amistad estelar, Círculo de Bellas Artes, Madrid, 2021, y concretamente en su capítulo «Parataxis poética como pharmakon para la transgresión filosófica: Hegel, Hölderlin y Adorno», de Marcela Vélez. 
Así, Hölderlin comenzó a entender esta comunión de toda la realidad bajo el símbolo del «Hen Kai Pan» y al principio unificador inmanente de la divinidad platónica como un Ser-Uno ${ }^{28}$, una unidad primigenia que sería anterior a todas las escisiones, y que expresaría la co-pertenencia de toda la realidad, en tanto que derivada de esta potencia originaria. Este Ser-Uno era la esfera donde se expresaría de forma más rica toda la realidad, no en tanto una mera superposición de entes ni como un ente supremo y vacío, sino como una unidad anterior a toda escisión, a la que pertenecerían de forma originaria todos los entes ${ }^{29}$.

En ese sentido, Hegel siguió a su amigo y se basó totalmente en los primeros años de Frankfurt en la interpretación neoplatónica de Platón, muy preocupada por ver en el pensamiento del ateniense estas expresiones de la divinidad. Y así tomó, de textos como El Banquete o Fedro, una concepción del amor que entendió como expresión de esta vida inmanente de la divinidad ${ }^{30}$, que superaba la unilateralidad de los amantes para reconocerlos en una unidad que no es una predestinación, ni un recuerdo de una vida pasada, sino la expresión misma de ese principio divino unitario que los crea y los constituye. En esa línea, podemos leer en uno de los fragmentos de esta época: «La religión es una con el amor. El amado no está opuesto a nosotros, es uno con nuestro ser; a veces vemos solo a nosotros mismos en él, y luego, de rechazo, es algo diferente a nosotros. Es un milagro que no terminamos de comprender» ${ }^{31}$.

Hegel, como podemos ver, vio en el amor un misterio: en una concepción oscilante, el amado pasa de ser uno con nosotros a ser diferente y como dirá más abajo en el mismo fragmento parafraseando el Fedro casi un Dios frente al que nos sacrificaríamos ${ }^{32}$. Y ninguna de ambas concepciones es suficiente, ya que el amor está expresando aquí una unión para la que la escisión de los conceptos de amante y amado genera una profunda inadecuación: ni el amante niega al amado en el amor, ni el amado niega al amante, sino que se produce una unificación que, en este momento, solo puede ser calificada por parte de Hegel como «misterio». Ese misterio parece que coincidirá en estos años con las intuiciones intelectuales de tipo estético, que identificará con la

28 BARRIOS, M., «La incidencia de la imagen de Grecia en la obra temprana de Hölderlin», op. cit., pp. 126-129 y 132. En esta concepción de Ser-Uno, parece que también jugaron un papel esencial las doctrinas no escritas de Platón (p. 128)

29 Es interesante notar aquí que, en estas concepciones, donde no solo Platón, sino también la influencia de autores como Herder se empieza a sentir, no se debe ver un panteísmo vulgar: Hölderlin no verá lo divino en cada cosa de la creación, sino que sentirá en la escisión del mundo creado una distancia con este Ser-Uno originario (Ibid., p. 129). Será ahí donde cobre sentido su crítica a la reflexión y a la proposición del entendimiento.

30 PLATÓN, El Banquete, Alianza Editorial, Madrid, 1999, pp. 86-87 y PLATÓN, Diálogos III. Fedón. Banquete. Fedro, Gredos, Madrid, 1989, pp. 354-355.

31 HEGEL, G. W. F., Escritos de Juventud, Fondo de Cultura Económica, Ciudad de México, 1978, p. 243.

32 Ibid., p. 243 y PLATÓN, Diálogos III. Fedón. Banquete. Fedro, op. cit., pp. 354-355. 
belleza platónica, con las que Hölderlin asumirá el mostrarse de este fondo de la vida. Un fondo que no es recuperable, pero que constituye a los amantes $^{33}$. En este misterio consistirá la religión del amor de estos primeros años en Frankfurt, entendiendo Hegel en esta etapa a la religión como el ámbito de la vida en el que se podría llegar a una expresión de esta unión que refleja la potencia inmanente de la vida.

Sin embargo, la incapacidad del amor para conciliar los elementos escindidos será, como bien nota Duque ${ }^{34}$, la razón del fracaso del amor como modo de expresión de la unidad pre-reflexiva. ¿iSe pueden conciliar meramente por el amor, a partir del momento de la intuición intelectual, las escisiones, como si dicha intuición impusiera un decreto externo al pensamiento a la manera del mandamiento del amor en el Sermón de la Montaña de Jesús ${ }^{35}$ ? ¿Hay alguna forma de poder conciliar lo escindido para encontrar una forma de expresión de esta unidad primigenia y de este campo plenificado de la existencia en el pensamiento? Aunque en esta etapa aún seguirá siendo dependiente de los planteamientos de Hölderlin, parece que los desarrollos que irá realizando con su círculo intelectual en Frankfurt serán fundamentales para su emancipación de los planteamientos hölderlinianos en los siguientes años. Y en ese sentido, será de gran importancia el estudio que realizará, con miembros de esta Liga de los Espíritus como von Sinclair, del escepticismo clásico y, especialmente, de diálogos platónicos como el Parménides, en una línea, por cierto, muy cercana a los planteamientos neoplatónicos de Marsilio Ficino. Como muy bien nota Hegel en su posterior artículo de Jena La relación del escepticismo con la filosofia, Marsilio Ficino ve un carácter divino en este diálogo, en el sentido de que su pensar basado en contradicciones permitiría la superación de lo mundano, siendo la puerta de entrada a un pensar la divinidad ${ }^{36}$. Así, Hegel y sus compañeros de la Liga de los espíritus ven en estos planteamientos del Parménides, mediante el método que se emplea ahí, la isostheneia, la capacidad de asumir lo finito y contrapuesto de los productos del entendimiento, siendo la puerta de entrada a la religión, donde ese fondo unificante puede percibirse, y desde el que se puede acceder, por lo tanto, a una comprensión mayor de la riqueza inherente de la vida. Y si bien esa necesidad de lo religioso, y esa necesidad en general de intuir este supuesto fondo del ser subyacente al darse de la realidad, no se mantendrá en Hegel, se empezará a ver con este escepticismo el camino para una superación inmanente de las insuficiencias de los productos de la reflexión en la

33 BARRIOS, M., «La incidencia de la imagen de Grecia en la obra temprana de Hölderlin», op. cit., pp. 127 y 132.

34 DUQUE, F., Historia de la filosofía moderna. La era de la crítica, op. cit, p. 358.

35 Ídem.

36 HEGEL, G. W. F., La Relación del Escepticismo con la Filosofía, op. cit., p. 65. 
reflexión, abriendo la posibilidad de que no tengamos que hacer referencia a un fondo de ser para expresar lo esencial de lo real, sino que entendamos esta superación dentro «de un proceso fundado en sí mismo», como comentaremos en la siguiente sección ${ }^{37}$.

Así, ya a finales de esta etapa, justo antes del giro sistemático de sus planteamientos, Hegel concebía ya la superación de la reflexión en dos ámbitos: por un lado, la filosofía, que sería una disciplina totalmente negativa de disolución y que alcanzaría la superación mediante el escepticismo y las connotaciones derivadas de la dialéctica platónica - en cuanto a lo fijado en el entendimiento como propedéutica a un ámbito más pleno de existencia-, y por otro, el de la religión, donde se daría lo positivo de ese ámbito de plenificación de la vida. $\mathrm{Y}$ en ese sentido se puede ver un paralelismo con las pretensiones de Hegel y cómo interpreta la filosofía platónica, entendiendo su dualismo como una apariencia más que como una realidad ontológica:

Platón, para representar al espíritu, es decir, lo divino fuera de su limitación, por un lado, y la comunidad de lo limitado con lo viviente, por el otro, separa lo que es vida pura de lo limitado mediante una diferencia en el tiempo: representa así los espíritus puros como si hubieran vivido por entero en la contemplación de lo divino y luego en la vida terrenal sólo existieran con la conciencia oscurecida de aquello ${ }^{38}$.

No hay dos mundos, sino solo una superación, dentro del mismo mundo, del limitado campo del entendimiento mediante la filosofía, siendo ésta la propedéutica para llegar a un ámbito de planificación de la existencia en la religión. La clave es analizar cómo se relaciona la vida con el campo de la reflexión, y así, si bien aún no habrá desarrollado su dialéctica, para lo que requirió aún ciertos elementos $^{39}$, ya hay textos, como el llamado Fragmento de sistema, en el

37 DUQUE, F., Historia de la Filosofía Moderna. La era de la crítica, op. cit., p. 354. Es interesante aquí contraponer el carácter unificador del amor frente a dinámicas como la del amo y el esclavo, cuya superación solo se puede dar en las escisiones, y no por referencia a una pacificación externa por decreto. Así comenzará, justo en esta etapa, a haber fragmentos donde expone dinámicas de dominación, por ejemplo, entre un perro y su amo, mostrando el darse de la intersubjetividad no en el éxtasis de la unión, sino en el darse de su escisión (HEGEL, G. W. F., Escritos de Juventud, op. cit., p. 255).

38 DUQUE, F., Historia de la Filosofía Moderna. La era de la crítica, op. cit., p. 357 y BARRIOS, M., «La incidencia de la imagen de Grecia en la obra temprana de Hölderlin», op. cit., p. 134.

39 Los elementos son, como define Düsing, por un lado, «el principio de desarrollo metódico de cada contraposición particular» y «una conexión metodológica de conjunto para su diversidad». Estos faltaron tanto en esta etapa como en los primeros años de Jena, hasta la transformación de su consideración de absoluto (Véase DÜSING, K., Das Problem der Subjektivität in Hegels Logik. Systematische und entwicklungsgeschitliche Untersuchungen zum Prinzip des Idealismus und zur Dialektik, Bouvier, Bonn, 1976, p. 73 y MONTECINOS, S., La asunción de la reflexión finita en la filosofía de G.W.F. Hegel, op. cit., p. 84). 
que identificó esta vida como «unidad de la unidad y la no-unidad» ${ }^{4041}$, elemento esencial para comprenderla.

¿Lo oyen? Es el eco del retumbar de los cañones de Jena. Pero aún faltarían algunos años y trabajo con lo platónico para desarrollar verdaderamente lo dialéctico en su pensamiento, así como para que brille en todo su esplendor la originalidad que lo distanciará de la dialéctica griega. Y es que Hegel no se quedó aquí, ya que como en aquella famosa carta de Hegel a Schelling afirmaba, «el ideal juvenil tuvo que tomar la forma de la reflexión, convirtiéndose en sistema» ${ }^{42}$. Son los años de Jena, que desembocarán en una epopeya de la conciencia mientras sonaban los cañonazos de la Europa en guerra. Y del joven Hegel habrá que pasar a Hegel, el estandarte del idealismo alemán. Platón aquí seguirá teniendo mucho que decir.

\section{Los comienzos en Jena: viejas herencias, nuevas navegaciones}

La carta que el joven Hegel mandó a su célebre amigo Friedrich Schelling, pidiéndole ayuda para introducirse en la carrera académica, tuvo resultado, y en 1801 nuestro joven filósofo pudo dejar los sufridos trabajos de preceptor que había tenido hasta entonces para dirigirse a la prestigiosa Universidad de Jena. Sin embargo, si de lo que debemos hablar es de sus planteamientos filosóficos, estos ya habían empezado a cambiar de forma definitoria en los últimos meses de su estancia en Frankfurt, abriendo el camino para los desarrollos que caracterizaron su filosofía en esta nueva etapa de Jena. Y en ese sentido, ya en la revisión que realizará de uno de sus textos no publicados de la época, La positividad de la religión cristiana, a partir de septiembre de 1800, podremos ver algunos elementos de los planteamientos sistemáticos que fundamentarán el pensamiento filosófico de Hegel en aquellos años:

Esta visión [Ansicht: ver que todo lo alto, lo puro y bueno del ser humano es algo divino] se convierte en algo positivo y estridente cuando la naturaleza humana es separada absolutamente de lo divino, sin mediación alguna entre ella misma y lo divino (excepto en el caso de un individuo), de modo que toda la conciencia humana de lo bueno y lo divino es denigrada al llevarla a la apatía y la aniquilación, como resultado de creer en algo

40 HEGEL, G. W. F., Escritos de Juventud, op. cit., p. 401.

41 Con Heinrich debemos notar aquí que habrá una evolución progresiva del pensamiento de la potencia unificadora como amor, a pensarla como vida al final del periodo de Frankfurt y ya, como vemos en el texto del Fragmento, como Espíritu, cuyas implicaciones y contenido irán variando y enriqueciéndose conforme avance el desarrollo del pensamiento hegeliano (HEINRICH, D., «Hegel y Hölderlin», Diálogos, op. cit., p. 64).

42 HEGEL, G. W. F., Escritos de Juventud, op. cit., p. 433. 
absolutamente extraño y prepotente [Übermachtige]. Se ve que una investigación sobre esto, en caso de ser conducida fundamentalmente por medio de conceptos, habría de llevar finalmente a un examen metafísico de la relación entre lo finito y lo infinito ${ }^{43}$.

Frente a las concepciones religiosas que habían dominado su producción filosófica durante la etapa de Frankfurt y su relación intelectual con Hölderlin, Hegel comenzará a entender, en estos albores del nuevo siglo, que la religión es insuficiente a la hora de producir la elevación de la vida finita a la vida infinita. $\mathrm{Y}$ es que esas visiones religiosas, y concretamente la creencia (Glaube), empiezan a ser vistas en este texto como experiencias unilaterales. ¿Podemos, a partir de una creencia religiosa, elevarnos a la vida infinita si entendemos el darse de esta vida infinita como algo separado absolutamente de la vida finita? $\mathrm{Pa}-$ rece que no y, de hecho, el coste que tendrá un planteamiento así lo podemos ver en el texto: si planteamos así la religión, la creencia se convertirá en algo «positivo y estridente», cuya verdad, en el fondo, no sería más que el resultado abstracto de la negación de lo reflexivo y lo finito ${ }^{44}$. Por ello, Hegel comienza en este texto a plantear una alternativa: es necesario «un examen metafísico de la relación entre lo finito y lo infinito». Y en ese sentido, rompiendo con los planteamientos religiosos de la etapa de Frankfurt, Hegel comenzará a entender la tarea de elevación de la vida finita a la infinita desde una perspectiva filosófica, que considera que permite una mediación entre lo finito y lo infinito. Será en ese ámbito donde podrá asumir los productos de la reflexión, sin las limitaciones de la religión, para llegar a un conocimiento de lo absoluto que supere los límites del conocimiento meramente reflexivo ${ }^{45}$.

Como decíamos anteriormente, estos primeros años en Jena fueron una larga travesía $^{46}$ : hasta 1805 no podemos identificar un pensamiento propiamente

43 Ibid., p. 426 y MONTECINOS, S., La asunción de la reflexión finita en la filosofía de G. W. F. Hegel, op. cit., p. 123. La traducción que hemos usado en esta cita no será la canónica de Ripalda, sino la usada por Montecinos a partir de la traducción directa del alemán de la versión original de los Frühe Schriften. Consideramos que es más adecuada al introducir el término «examen metafísico», que lo ligará con los desarrollos posteriores en los primeros años de Jena. Aun así, citamos también la página de la traducción de Ripalda, donde se pueden ver las continuidades de ambas traducciones.

44 MONTECINOS, S., La asunción de la reflexión finita en la filosofía de G. W. F. Hegel, op. cit., p. 121.

45 Es esencial notar en este punto que, para ello, se necesitará una modificación de la comprensión de la razón en tanto que, como nota Montecinos, Hegel ya no la entenderá como una facultad que meramente «indica un más-allá de la reflexión, sino como un modo de conocimiento que asume la reflexión y sus determinaciones desde sí mismas» (MONTECINOS, S., «Máscaras del escepticismo en la filosofía hegeliana», op. cit., p. 121). Esto será esencial para comprender el concepto de «reflexión filosófica» que se moverá en la lógica escéptica.

46 No debemos obviar en este punto, sin embargo, que en la época de Jena será la primera donde, por fin, tendremos obras publicadas de Hegel. Estas se dividirán entre sus artículos en la revista Kritisches Journal der Philosophie, donde compartirá páginas con su nuevo protector en esta 
dialéctico en Hegel, y hasta aquel momento sus planteamientos sufrieron una evolución progresiva en la que se pueden identificar al menos hasta tres lógi$\mathrm{cas}^{47}$. Sin embargo, es posible notar, además de ciertos elementos comunes de los primeros años de Jena, cómo lo platónico tendrá un papel central en la configuración de estos planteamientos y cómo, ya desde la lógica de 1801-1802, será un antecedente de especial importancia para el pensamiento propiamente dialéctico. Por ello, es interesante ver cuáles serán los elementos fundamentales de estos primeros desarrollos de Jena, y cuál será la influencia en ellos del pensamiento platónico.

En primer lugar, debemos tener en cuenta que los desarrollos de los primeros años de Jena fueron dependientes de los enfoques sustancialistas de Schelling. Y es que Hegel, a pesar de que rompió con los planteamientos religiosos y la creencia como modo de unificación, aún sigue en estos años concibiendo, con Schelling, una «cierta forma absoluta de intuición que daría lugar al saber especulativo de lo absoluto», entendido como sustancia ${ }^{48}$. Pero lo interesante de esta etapa fue que Hegel diferenció en dos ámbitos la filosofía, una estructura que nos recuerda al papel que jugaban la religión y la propia filosofía en la etapa de Frankfurt: primero, una metafísica, como parte positiva de la filosofía en la que se dará ese conocimiento de carácter intuitivo del absoluto del que hablábamos antes, y una lógica, como parte negativa, que se ocupará de asumir los productos de la reflexión.

Es justo en las lógicas de aquellos años, y especialmente en la lógica que esbozó Hegel entre 1801 y 1802, donde podemos aislar la importantísima influencia que Platón tendrá en estos primeros intentos de asumir los productos finitos de la reflexión. Y es que, a partir de esta primera lógica de Jena (18011802) Hegel se apropiará de los planteamientos del escepticismo antiguo y de la dialéctica platónica expuesta en el Parménides para estructurar lo que será, al menos en los primeros años de Jena, una lógica escéptica ${ }^{49}$. Así, Hegel verá en

etapa, Schelling, y destacarán Fey Saber o La Relación del escepticismo con la filosofía (HEGEL, G. W. F., La Relación del escepticismo con la filosofía, op. cit.), y su obra completa Sobre la diferencia de los sistemas de filosofía de Schelling y Fichte (HEGEL, G. W. F., Sobre la diferencia de los sistemas de filosofía de Schelling y Fichte, Alianza Universidad, Madrid, 1989). También en esta etapa fue donde comenzó a dar clases en la Universidad con asignaturas como Historia de la Filosofía. Habría sido de gran utilidad para este trabajo que se hubieran conservado los textos que preparó para dichas clases, los cuales parece que fueron una de las fuentes que usó Michelet para la elaboración de su compilación Lecciones sobre Historia de la Filosofía, pero tristemente se perdieron (BARRIOS, M., «Hegel: Una interpretación del platonismo», Anales del Seminario de Metafísica, op. cit., pp. 126 y ss.), estando mezcladas en esta compilación fuentes de distintas etapas.

47 MONTECINOS, S., La asunción de la reflexión finita en la filosofía de G. W. F. Hegel, op. cit., p. 146.

48 Ibid., p. 23.

49 Es importante notar que esta apropiación se ve hasta en los términos que usa, llegando a utilizar el término «múltiple», en línea con el Parménides, para referirse a la diferencia (GADAMER, H. G., La dialéctica de Hegel, Ediciones Cátedra, Madrid, 2000, p. 21). 
los planteamientos del escepticismo antiguo - no así en el moderno ${ }^{50}$ - y en los planteamientos dialécticos de Platón la base para una asunción de las aseveraciones finitas del entendimiento a partir del método que usaron este grupo de autores, la isostheneia, o método de la igualdad de validez. Y en esa línea, como el propio Hegel nos menciona en su famoso artículo La Relación del Escepticismo con la Filosofía, el filósofo suabo verá en Platón el ejemplo más claro del tipo de escepticismo $^{51}$ en el que basó su lógica en los primeros años de Jena:

¿Qué documento y sistema más acabado y evidente de auténtico escepticismo podríamos encontrar en la filosofía platónica que el Parménides, el cual abarca y destruye todo el ámbito de ese saber a través de conceptos del entendimiento? Este escepticismo platónico no se dirige a dudar de estas verdades del entendimiento, el cual conoce las cosas como múltiples, como un todo que consiste en partes, como un surgir y un desaparecer, una pluralidad, una similitud, etc., y hace afirmaciones objetivas de esa clase, sino que se dirige a negar toda verdad de un conocer tal [...] Este escepticismo que entra en escena en su pura figura explícita en el Parménides cabe encontrarlo implicite, sin embargo, en todo autentico sistema filosófico, pues es el lado libre de toda filosofía de esa índole ${ }^{52}$.

Así pues, ¿en qué consistirá ese método que compartirán los filósofos escépticos antiguos y el Parménides? La clave estará en el llamado argumento de Palámedes ${ }^{53}$, que recoge Platón en el Parménides ${ }^{54}$, y que afirma lo que sigue: «para cada proposición hay que investigar también su contraria». Y así, investigando una proposición y su contraria, en el entendimiento parece que se llega al principio fundamental del escepticismo: «panti logoi logos isos antiketai». Es decir: «contra todo argumento hay otro argumento igual en el lado

50 Hegel hará en esta etapa una fuerte crítica al escepticismo moderno, cuya personificación encontrará en Schulze y su filosofía basada en los hechos inmediatos de la conciencia, y que se diferenciaría profundamente del antiguo. Para Hegel este escepticismo, a diferencia del antiguo, carecería de lo interesante del carácter metódico del escepticismo antiguo, y, sobre todo, de una verdadera fluidificación de las oposiciones, extraordinariamente fijadas en su concepción de hechos de la conciencia. En el fondo, este escepticismo moderno no sería sino un profundo dogmatismo que no lograría captar en toda su amplitud la riqueza del escepticismo antiguo.

51 Es importante notar que Platón no fue parte del escepticismo antiguo. Hegel valoró de forma muy importante en esta etapa a autores como Sexto Empírico, miembro de dicha escuela filosófica, o Pirrón, y reconoció una continuidad entre los planteamientos que se pueden ver en obras platónicas como el Parménides y los trabajos de Sexto. Sin embargo, Platón y la tradición dialéctica eleática fueron anteriores a los desarrollos de los escépticos, con los que compartieron el pensar por contradicciones y la isostheneia.

52 HEGEL, G.W. F., La relación del escepticismo con la filosofía, op. cit., pp. 65-66, y MONTECINOS, S., La asunción de la reflexión finita en G. W. F. Hegel, op. cit., p. 188.

53 GADAMER, H. G., La dialéctica de Hegel, op. cit., p. 32.

54 PLATÓN, Parménides, Alianza Editorial, Madrid, 2013, pp. 83-84. 
opuesto» ${ }^{55}$. Este procedimiento estará constantemente generando antinomias, lo que podemos ver de forma radicalizada en el diálogo del ateniense, y, si asumimos el principio de contradicción, llegaríamos a una aporía: si todo argumento tiene otro argumento de igual validez contradictorio, de acuerdo con el principio de contradicción, ninguno será cierto. Sin embargo, esta aporía no será reconocida de manera puramente negativa por los escépticos ${ }^{56}$, en los que habrá un lado positivo: la epojé o suspensión de juicio, que serenamente acepta la naturaleza contradictoria de lo real y abandona la «desesperación» por el constante carácter contradictorio del devenir ${ }^{57}$.

Hegel también asumió en esta etapa, como los escépticos, un lado negativo y un lado positivo de dicho proceso de generación de antinomias en el que consistía su lógica escéptica. Y es que, teniendo en cuenta la naturaleza de la reflexión y su generación de contraposiciones, este método de la isostheneia concluía en el resultado negativo de disolver la fijación de los productos del entendimiento. Así, en ese sentido, como nota en el fragmento de $\mathrm{La} R e^{-}$ lación, este método «se dirige a negar toda verdad de un conocer tal», es decir, del conocer asociado a productos finitos y unilaterales del entendimiento. Sin embargo, también había un lado positivo: la apertura de una nueva esfera de conocimiento más elevada, que se identifica con el conocimiento metafísico. Y en este sentido, este método escéptico cumplirá la tarea que ya empezaba a ser intuida en Frankfurt: ya no se habla de este método de igualdad de validez como puerta de entrada a la divinidad, pero sí es fundamental en estos planteamientos para entrar en un conocimiento más elevado, que es el conocimiento metafísico del absoluto.

Como conocemos, estos planteamientos fueron planteamientos provisionales que estaban sujetos a evolución durante aquellos años y que se modificaron profundamente una vez Hegel llegó al pensamiento propiamente dialéctico a partir de 1805. Sin embargo, una vez expuestos estos planteamientos de los primeros años en Jena, y la influencia de Platón y del escepticismo antiguo en ellos, es interesante notar varias cosas:

1) En primer lugar, nos gustaría hacer notar en este punto el paralelismo que se puede encontrar entre la manera de entender el conocimiento de Platón y el de Hegel. Y es que, si bien en el Parménides es complicado encontrar,

55 HEGEL, G. W. F., La relación del escepticismo con la filosofía, op. cit., p. 66.

56 Esto no es aplicable al Parménides, como bien nota Gadamer (GADAMER, H. G., La dialéctica de Hegel, op. cit., p. 33). Si bien Hegel entenderá, y sobre todo en línea con otros textos de Platón como El Sofista, un momento positivo en el diálogo platónico, si atendemos a la literalidad del texto, termina de forma totalmente aporética: «Digámoslo entonces, y también que, según parece, tanto que haya Uno como que no lo hay, él y los Otros, con respecto a sí mismos y en sus relaciones mutuas, son absolutamente todo y no lo son, parecen serlo y no lo parecen» (PLATÓN, Parménides, op. cit., p. 172).

57 MONTECINOS, S., «Máscaras del escepticismo en la filosofía hegeliana», op. cit., p. 132. 
dentro del texto, un lado positivo, en muchas de las obras de Platón se puede ver una elevación hacia conocimientos superiores que partían de un cuestionamiento y una dialéctica sobre los elementos y certezas que componían la conciencia natural $^{58}$. Y así, como bien nota Montecinos (y el propio Hegel en sus Lecciones), se podría hablar de que ambos conciben el conocimiento como un proceso de elevación, que en el caso de Platón se elevará hacia lo universal, y en Hegel, hacia lo absoluto ${ }^{59}$.

2) Y, en segundo lugar, es interesante observar las tensiones que empezaron a brotar con ciertos elementos emergentes del pensamiento de Hegel. Y así, el escepticismo de las lógicas de sus primeros tiempos en Jena será la puerta de entrada de un modelo de reflexión filosófica en la que, como nota Monteci$\operatorname{nos}^{60}$, ya entrará la razón en el entendimiento, y servirá como nexo entre esta disolución de la rigidez de las oposiciones por el escepticismo y el conocimiento de lo absoluto en la metafísica, exponiéndolas racionalmente. Pero dicha reflexión tendrá problemas, teniendo cierta incompatibilidad con las concepciones de absoluto sustancial que tomó Hegel de Schelling ${ }^{61}$, y, en ese sentido, un anticipo de lo que comenzaremos a estudiar ahora: los primeros desarrollos dialécticos de Hegel.

\section{La querelle des anciens et des modernes: la tarea de la Modernidad y las distancias entre las dialécticas de Hegel y de Platón}

Nos queda, pues, un último momento en nuestra investigación: ¿qué decir de las primeras configuraciones de la dialéctica hegeliana, y qué papel tuvo Platón en ellas? Como ya hemos comentado anteriormente, los primeros planteamientos dialécticos de Hegel no llegaron antes de 1805. Ya quedaba poco para el desarrollo de su primera gran obra, la Fenomenología del espiritu, publicada en

58 GADAMER, H. G., La dialéctica de Hegel, op. cit, p. 14.

59 MONTECINOS, S., «Conexiones metodológicas entre las filosofías de Platón y Hegel: la lectura platónica de la dialéctica hegeliana», op. cit., p. 111, y HEGEL, G. W. F., Lecciones sobre Historia de la Filosofía II, Fondo de Cultura Económica, Ciudad de México, 2005, p. 162.

60 MONTECINOS, S., La asunción de la reflexión finita en la filosofía de G. W. F. Hegel, op. cit., p. 167 yss.

61 Es profundamente problemática la comprensión de esta «reflexión filosófica» y esta razón en el entendimiento, de la que habló Hegel en obras como Sobre la diferencia de los sistemas de filosofía de Schelling y Fichte, por el hecho de que Hegel aquí sigue pensando, con Schelling, en un absoluto sustancial y punto de indiferencia, mientras que la reflexión es el campo de la diferencia. En ese sentido, estos desarrollos parecen ser el canto del gallo de los próximos desarrollos dialécticos una vez se aparta de los planteamientos de su amigo, y muestran, como comenta Montecinos, una cierta tensión entre las concepciones dialécticas que empiezan a nacer y las concepciones sustancialistas de Schelling (Idem). 
$1807^{62}$, y también el suabo estaba en los últimos años de su estancia en Jena, de la cual partió tras la crisis por las Guerras Napoleónicas. Pero si algo marcó la irrupción de los primeros planteamientos dialécticos en Hegel, esto fue el alejamiento que tuvo con el que había sido su protector en Jena, amigo y compañero desde el Stift, Friedrich Schelling. Y quizá para entenderlo mejor, sea interesante leer el párrafo crítico que Hegel dedicó a los planteamientos de Schelling en su Fenomenología:

Y encima, este formalismo afirma que esta monotonía y esta universalidad abstracta son lo absoluto; y asegura que quienes no se dan por satisfechos con ese modo de ver revelan con ello su incapacidad para adueñarse del punto de vista de lo absoluto y mantenerse firmemente en él. [...] Contraponer este saber único de que en lo absoluto todo es igual al conocimiento diferenciador y lleno, o que busca y exige ser colmado - o bien, hacer pasar su absoluto por la noche en la que todos los gatos son pardos - es la ingenuidad del vacío en el conocimiento ${ }^{63}$.

Hegel, si bien había sido dependiente de las concepciones del absoluto de Schelling los primeros años en Jena, tras la emergencia de las primeras configuraciones dialécticas, rompe de forma clara con los planteamientos de su antiguo amigo. Ya, en el punto en el que se encontraba el suabo, no eran satisfactorias las consideraciones de un absoluto puramente sustancial y que se identificara con el punto de indiferencia. Y es que el desarrollo cada vez más complejo de las lógicas, que fue ensayando durante toda la etapa de Jena, empezó a entrar en conflicto con estos planteamientos de Schelling: ¿era compatible una reflexión especulativa, un papel de la razón en el ámbito del entendimiento, si nuestra idea de absoluto era una monotonía y una universalidad abstracta donde «todos los gatos son pardos»? Hegel no lo vio así y se produjo un cambio muy profundo en sus concepciones sobre lo absoluto que determinó y facilitó sus desarrollos dialécticos: desde entonces, el absoluto para él no fue simplemente sustancia, sino que debía reconocerse también como sujeto ${ }^{64}$.

62 Teniendo en cuenta el carácter monumental de la Fenomenología, podría surgir una pregunta: ¿empezó a ser elaborada antes del desarrollo de sus concepciones dialécticas? No, el periodo de elaboración de la Fenomenología fue un periodo extraordinariamente corto, en el que, además, se intercalaron diversos problemas: además de problemas personales, como el nacimiento de un hijo ilegítimo, tuvo que lidiar con la guerra que había estallado y hasta la propia Jena fue campo de batalla mientras Hegel terminaba los últimos retoques de su primera gran obra (HYPPOLITE, J., Génesis y estructura de la Fenomenología del Espíritu de Hegel, Ediciones Península, Madrid, 1974, pp. 49 y ss.). Por ello, por un lado, esta obra se puede incluir claramente en los primeros desarrollos dialécticos que trataremos aquí y, además, desde nuestro punto de vista, en el repertorio de milagros y leyendas que configuran la mística de ciertos filósofos.

63 HEGEL, G. W. F., Fenomenología del Espíritu, op. cit., p. 71.

64 Ibid., pp. 71-73 y 943. 
Dichos planteamientos sobre lo absoluto supusieron un profundo cambio de rumbo respecto a lo expuesto por los que fueron sus amigos y principales fuentes de influencia en Frankfurt y Jena, Hölderlin y Schelling. Y así, si ya no consideraba que, por un lado el absoluto se pudiera identificar con un absoluto sustancial y punto de indiferencia a la manera de Schelling, ni tampoco eran satisfactorios los planteamientos de Hölderlin de un fondo de vida subyacente que fuera fuente de todas las escisiones del entendimiento, sus planteamientos sobre lo absoluto provocaron una profunda revolución en sus concepciones que hacía irrelevante el plantearse la necesidad de una intuición para pensar una divinidad o una potencia activa inherente al mundo. Sus concepciones profundamente activas e inherentes al mundo del absoluto desembocaban en el planteamiento de que ahora no había nada externo al proceso de darse de lo real ${ }^{65}$, por lo que no necesitamos ninguna apelación a una potencia más o menos externa: si queremos conocer lo absoluto nos tenemos que limitar al proceso de darse de lo real y nada más.

Y la primera consecuencia lógica -y nunca mejor dicho- de este giro fue clara: ya no era necesario un conocimiento metafísico intuitivo a la manera que Hegel lo había conducido por influencia de Schelling. Ahora la ciencia especulativa base será la misma lógica, y en ese sentido, concepciones como reflexión filosófica o reflexión especulativa se profundizaron, entendiendo una profunda compenetración entre lo racional y lo reflexivo.

En este marco, Hegel comenzó a comprender que no era necesaria una potencia externa para fundamentar la asunción de la finitud de los productos del entendimiento - que, por otro lado, requerían un nuevo marco que permitiera dicha asunción, basado ahora en la estructura esencia-apariencia ${ }^{66}$ - sino que tendrían en sí mismos la ruina y potencia para superar su finitud. Y es que, en ese sentido, Hegel comenzaba a pensar (aunque se pueden ver antecedentes de esta idea en textos de años anteriores) que la positividad de algo implicaba su negación, y asimismo tenía en si misma implícita la entera relación ${ }^{67}$.

65 DUQUE, Félix, Historia de la Filosofía Moderna. La era de la crítica, op. cit., p. 354.

66 MONTECINOS, S., La asunción de la reflexión finita en la filosofía de G. W. F. Hegel, op. cit., p. 24.

67 Es muy interesante este pequeño fragmento de los primeros años de Jena, concretamente de Fe y Saber, donde ya se mostraba la unidad prerreflexiva con la que entendió luego Hegel la identidad de la identidad y la diferencia: «[...] Kant mismo distingue la abstracción del yo, o la identidad [abstracta y vacía] del entendimiento, del verdadero yo como principio, en cuanto absoluta identidad sintética originaria. Así, Kant ha resuelto realmente su pregunta: ¿cómo son posibles los juicios sintéticos a priori? Son posibles mediante la absoluta identidad originaria de lo múltiple, respecto de la que, como de lo incondicionado mismo, se separa ella misma, como lo particular de lo universal, como en la forma de un juicio se separan sujeto y predicado. Lo racional, o como Kant se expresa, lo apriorístico de este juicio, la absoluta identidad como concepto intermedio, no se presenta en el juicio, sino en el razonamiento» (MONTECINOS, S., «Conexiones metodológicas entre las filosofías de Platón y Hegel: la lectura platónica de la dialéctica hegeliana», op. cit., p. 123). Aquí habría una clara disputa entre los planteamientos de Kant y de Hegel: ¿es anterior o posterior la síntesis de lo múltiple a la fijación de los elementos 
$\mathrm{Y}$ así, si bien puede haber una apariencia de finitud y fijación que esclerotice en el ámbito de entendimiento a los productos de reflexión, en su positividad está inserto el camino para su asunción y para su superación, desvelando -aletheia - en tal proceso una verdad superior, un conocimiento especulativo, que muestre un ámbito superior de lo real, oscurecido por las apariencias de finitud en las que cae el entendimiento. Y así, la implícita unión de la unión y de la no-unión abre un camino para una asunción de los limitados productos del entendimiento y de sus apariencias.

Aquí es ya muy difícil ignorar la profundización de los planteamientos que, insertos inicialmente en una lógica escéptica, empezaron a suponer una apropiación por parte de Hegel de la antigua dialéctica platónica. Y es que, ahora, la superación de lo finito no depende como tal de un método escéptico, sino más bien el propio devenir de lo real muestra insertos estos planteamientos y esta superación inmanente de las limitaciones de la reflexión. Por ello, los planteamientos dialécticos que tomó de las fuentes antiguas y especialmente de Platón comenzaron a ser la mejor expresión para exponer el proceso de darse de lo real en el que estamos insertos como seres humanos ${ }^{68}$. Sin embargo, debemos hacernos una pregunta: ¿ $\mathrm{f}$ ue una apropiación pasiva de la dialéctica griega

en la reflexión? Para Kant, la síntesis será posterior, para Hegel anterior, y en ese sentido Hegel aquí está anticipando los elementos implicativos del tiempo o los existenciales presentes en autores como Husserl o Heidegger.

68 No podemos, en este punto, ignorar los comentarios críticos que hizo Martin Heidegger en su célebre artículo «Hegel y los griegos», jugando, precisamente, con el término, mencionado arriba, aletheia (HEIDEGGER, M., «Hegel y los griegos», Revista de Filosofía, 1966, Vol. 13 (1), pp. 115-130). ¿Hegel fue leal en la construcción de su dialéctica a los planteamientos griegos y su concepción de la verdad o esta imagen de lo griego -y de Platón- presente en su obra estuvo imbuida por su interpretación de la filosofía de la historia que fue insuficiente para recoger una riqueza, quizá aún impensada actualmente, del pensamiento griego? Si bien los planteamientos de Heidegger en el artículo son profundamente interesantes, sí queremos advertir la distancia de la línea de investigación de este trabajo con una de las afirmaciones centrales del autor alemán en este texto: «Con respecto a Hegel y los griegos, esto significa que a toda afirmación historiográfica, correcta o incorrecta, antecede el que Hegel ha experimentado la esencia de la historia desde la esencia del ser, en el sentido de la absoluta subjetividad» (Ibid., pp. 126-127). Hegel pudo ser más o menos leal a los planteamientos griegos, pero ¿verdaderamente podemos decir que su interpretación de la esencia de la historia desde el sentido de la absoluta subjetividad precede a su lectura de Platón en estas etapas? El hecho de que su ruptura con Schelling y su comprensión del absoluto como sujeto fuera ya en el 1805, sus ambivalencias con la filosofía de Fichte o la cuestión de que la parte más importante de su lectura de Platón se diera entre sus etapas de Frankfurt y sus primeros años en Jena nos hacen sospechar que más que una lectura de Platón modificada por su concepción filosófica, su concepción filosófica fue construida a partir de una determinada (más o menos leal históricamente) lectura de Platón. Por ello, si bien lo griego y la propia interpretación posterior de la filosofía platónica estuvo profundamente determinada por su interpretación de la filosofía y de la historia, en este trabajo estamos planteando una relación distinta de Hegel con los griegos y Platón a la que propone Heidegger, o, al menos, leída en otro momento del desarrollo hegeliano: una relación que antecede a la constitución de la filosofía dialéctica del suabo y que fue una de las fuentes de las que bebió en su juventud. 
la que realizó Hegel o vemos en estas primeras configuraciones dialécticas hegelianas una originalidad que no estaba en Platón y los antiguos? Y para entenderlo, quizá es interesante irnos a un momento de la Fenomenología donde el suabo expuso las diferencias entre las tareas de los modernos y los antiguos:

El tipo de estudio de los tiempos antiguos se distingue del de los tiempos modernos en que aquél era, en rigor, el proceso de formación plena de la conciencia natural. Ésta se remontaba hasta una universalidad corroborada por los hechos, al experimentarse especialmente en cada parte de su ser allí y al filosofar sobre todo el acaecer. Por el contrario, en la época moderna el individuo se encuentra con la forma abstracta ya preparada; el esfuerzo de captarla y apropiársela es más bien el brote no mediado de lo interior y la abreviatura de lo universal más bien que su emanación de lo concreto y de la múltiple variedad de la existencia. He ahí por qué ahora no se trata tanto de purificar al individuo de lo sensible inmediato y de convertirlo en sustancia pensada y pensante, sino más bien de lo contrario, es decir, de realizar y animar espiritualmente lo universal mediante la superación de los pensamientos fijos y determinados. Pero es mucho más difícil hacer que los pensamientos fijos cobren fluidez, que hacer fluir a la existencia sensible ${ }^{69}$.

El objetivo y la tarea de los modernos es profundamente distinta a la de los antiguos. Si bien ellos tenían que arrancar del devenir y el darse de las cosas universales con los que pensar el mundo ${ }^{70}$, nosotros tenemos que vivificar el mundo escindido por el papel dominante del entendimiento en nuestra cultura y nuestra racionalidad. Y si bien ambas tareas son diametralmente opuestas, los planteamientos dialécticos fueron profundamente interesantes para ambos mundos.

Y es que, por un lado, la dialéctica, al ser un pensamiento regido por la generación de contradicciones, generaba una posibilidad de pensar el movimiento y el devenir natural en el que estaban insertas las sociedades antiguas ${ }^{71}$. Pero,

69 HEGEL, G. W. F., La Fenomenología del espíritu, op. cit., p. 93, y GADAMER, H. G., La dialéctica de Hegel, op. cit., pp. 13-14.

70 No podemos dejar de ver aquí, en adición a lo comentado en la nota 69, que dicha comprensión de lo griego, en el marco de su filosofía de la historia, entrará en tensión con las consideraciones que hizo posteriormente Heidegger en su Nietzsche, respecto a la época de la presencia de los griegos y la época de la subjetividad y la imagen del mundo de los modernos (HEIDEGGER, M., Nietzsche, Editorial Ariel, Madrid, 2013, pp. 624-682). Para la respuesta del autor alemán al suabo, recomendamos el ya mencionado arriba HEIDEGGER, M., «Hegel y los griegos», Revista de Filosofía, op. cit., 115-130.

71 Es importante notar la esencial relación que se vio entre contradicción y movimiento (GADAMER, H. G., La dialéctica de Hegel, op. cit., p. 22). Así, «la contradicción que demuestra Zenón en el concepto del movimiento ha de ser, según Hegel, admitida como tal, sólo que eso no significa nada contra el movimiento, sino que, por el contrario, demuestra la existencia de la contradicción. "Si algo se mueve, ello no es por estar aquí en este ahora y en otro ahora allí (allí donde esto está en algún tiempo dado, no está precisamente en movimiento, sino en reposo), 
además, al ser un pensamiento del movimiento, permite fluidificar y superar la fijación con la que el entendimiento había fijado al mundo en la Modernidad. Por ello, ambas son caminos profundamente adecuados para pensar ambos mundos, siendo, si cabe, profundamente más necesaria en la tarea de la Modernidad que en la tarea de la Antigüedad clásica, de la que surgió originalmente. Sin embargo, si afinamos un poco más el análisis, podemos empezar a ver diferencias importantes entre los planteamientos de Hegel y las dialécticas antiguas, y, especialmente, respecto a la que fue la forma más elevada de dialéctica antigua al parecer de Hegel: la dialéctica platónica.

De acuerdo con Gadamer, podemos identificar tres momentos fundamentales que constituyeron la dialéctica hegeliana:

Primero: el pensar es pensar de algo en sí mismo, para sí mismo. Segundo: en cuanto tal es por necesidad pensamiento conjunto de determinaciones contradictorias. Tercero: la unidad de las determinaciones contradictorias, en cuanto éstas son superadas en una unidad, tiene la naturaleza propia del sí mismo ${ }^{72}$.

¿Podemos encontrar estos elementos en las dialécticas antiguas? En primer lugar, ese pensar de algo en sí mismo, para sí mismo, el intento de pensar puramente lo pensado sin ningún tipo de elemento externo que modifique, claramente está en las distintas dialécticas antiguas. La radicalización en el pensar de elementos como lo «múltiple», llevando hasta las últimas consecuencias lo que le es propio, en autores como Zenón muestra claramente estos intentos ${ }^{73}$, y el pensar de Platón a partir de las certezas de la conciencia natural en sus diálogos socráticos claramente es también un ejemplo de este intento de pensar puramente y hasta las últimas consecuencias dichas certezas. Por ello, y asumiendo que esto también está presente en Hegel, al que veremos pensar puramente lo implícito que está ya presente en nuestras certezas naturales, podemos afirmar que en este punto sí hay un claro paralelo entre dialécticas. En segundo

sino tan sólo por estar, en uno y el mismo ahora, aquí y no aquí, por estar y al mismo tiempo no estar en este aquí". En el fenómeno del movimiento cobra el espíritu certeza de su mismidad por primera vez, y de una manera inmediatamente intuitiva. Y ello ocurre porque el intento de apelar al movimiento como algo que es conduce a una contradicción. A lo que se mueve no le conviene en su ser el predicado de estar aquí ni tampoco el de estar allí. El movimiento mismo no es ningún predicado de lo que es movido, ningún estado en el cual se encuentre un ente, sino una determinación del ser de tipo sumamente peculiar: el movimiento es "el concepto de la verdadera alma del mundo; nosotros estamos acostumbrados a considerarlo como un predicado, como un estado [-porque nuestro modo de captar y de apelar es en cuanto tal predicativo y por ello tiene un efecto de fijación-], pero de hecho es el sí mismo, el sujeto como sujeto, lo que permanece de la desaparición"» (Idem)

72 Ibid., p. 31.

73 Idem. 
lugar, también aquel caer en contradicciones claramente estuvo presente en ambos modelos de dialéctica. Y es que, por un lado, en Hegel necesariamente se configuran contradicciones a partir del pensar puramente elementos que tienen insertos en su propia positividad su negatividad. Así, en tanto que necesariamente está implícita la unidad de la unidad y la no-unidad en cada elemento producido por la reflexión, se debe caer en la contradicción a partir de su pensamiento y de su desarrollo, y esta será parte del conocimiento especulativo y del darse de lo real. Esto es paralelo para los dialécticos antiguos: ese pensamiento puro de las determinaciones necesariamente cae en el panti logoi logos isos antiketai, mostrando la profunda aporía en la que cae el conocimiento y que es llevada al extremo por Platón en el Parménides. Sin embargo, en el último elemento no está tan clara la continuidad.

Hegel planteó que en el único de los dialécticos antiguos donde puede verse este planteamiento fue en Platón (Gadamer, 2000, 32-ss,). Y en ese sentido Hegel hace una interpretación conjunta de dos de los últimos diálogos que compondrán la filosofía de Platón: Parménides y El Sofista ${ }^{74} 75$. Si bien ya hemos hablado ampliamente del Parménides como un diálogo en el que se llevarán al extremo las consecuencias dialécticas de la investigación de cada argumento y su contrario, El Sofista es un diálogo también profundamente interesante a la hora de entender la complejización que Platón realizó de sus planteamientos dialécticos -y ontológicos- en estas últimas etapas de su vida. Y es que, en dicho diálogo, Platón se enfrentó a la cuestión del No-Ser; yendo a la caza de la determinación del sofista, surgía una pregunta de una profunda gravedad: ¿puede de alguna manera el No-Ser ser? Hegel interpretó la propuesta de este

74 ¿Tuvo esta interpretación conjunta algún tipo de influencia en el desarrollo de los planteamientos dialécticos de Hegel? Para responder a esta pregunta habría sido interesante haber conservado el cuaderno para las lecciones que tuvo que comenzar a impartir justo en 1804-1805 sobre historia de la filosofía y que el compilador de sus lecciones, Michelet, usó como una de las fuentes para realizarlas. Sin embargo, este cuaderno se perdió, y solo podremos usar en este trabajo como fuente lo mencionado en la compilación de Michelet, cuyas principales fuentes fueron los apuntes realizados por alumnos en la posterior etapa de Berlín (BARRIOS, M., «Hegel: una interpretación del platonismo», op. cit., pp. 127 y 137). Por ello, no podemos hacer aquí un juicio del papel que tuvieron dichas interpretaciones en la gestación de la dialéctica hegeliana, o si esta interpretación fue posterior a la génesis de estos planteamientos. Sin embargo, es evidente que el profundo valor que dio Hegel a los planteamientos platónicos y la interpretación profundamente cercana de ellos como antecedentes de su pensamiento no fue abandonada en épocas posteriores.

75 La valoración de los textos de la última etapa de Platón, realizada gracias a esta primera influencia de von Sinclair y su estudio del escepticismo antiguo, fue esencial a la hora de volver a valorar unos textos, como Parménides, El Sofista o Filebo, que estaban muy olvidados en la época, sobre los que se llegó a generar, en el siglo XIX, disputas sobre su autenticidad, como bien nota Gadamer (GADAMER, H. G., La dialéctica de Hegel, op. cit., p. 13). Por ello, no solo es importante esta recepción de lo platónico a la hora de guiar el camino hacia la dialéctica hegeliana, sino también el pensamiento hegeliano ha sido un pensamiento esencial para la recepción y valorización de ciertos textos de Platón en la Modernidad. 
diálogo de una manera profundamente cercana a sus posiciones, y en ese sentido leyó en el pasaje 259b del diálogo: «Lo difícil y verdadero es esto: que lo que es lo otro es lo mismo. Y ciertamente en uno y el mismo respecto, por el mismo lado» ${ }^{76}$. ¡Aquí lo tenemos! Platón parece que asumió lo que volvió a ser patente en Hegel, esa unidad previa y constituyente de la unidad y la diferencia. Sin embargo, la interpretación que hace Hegel parece que está profundamente alejada de la realidad del diálogo. Dicho pasaje dice más bien:

[...] lo difícil y verdadero es, cuando alguien dice que lo mismo es de alguna manera también diferente, seguirle hasta averiguar en qué sentido y en qué respecto ello es así. Si no se caracteriza este respecto, y se lo deja indeterminado, entonces concebir lo mismo como diferente y producir de esta manera contradicciones es, por el contrario, expresamente caracterizado como una tarea inútil que sólo tiene interés para un aprendiz ${ }^{77}$.

En este sentido, si atendemos al pasaje original, pocas cosas hay tan opuestas al objeto de Hegel con el tercer momento de su dialéctica. Y es que, más que una anticipación de la unidad de la unidad y la no-unidad, Platón aquí lo que está haciendo es una anticipación del principio de no contradicción aristotélico, separando en distintos sentidos el darse de lo que entra en contradicción.

¿Por qué esa diferencia entre los planteamientos dialécticos de Hegel y Platón? La cuestión parece ser que Hegel ve en estos diálogos de Platón la superación de algo que, sin embargo, criticó a la propia dialéctica de Platón: su carácter objetivo. En el pensamiento de la problemática de la contradicción, de la diferencia y del no ser, Platón complejiza de forma muy interesante sus concepciones ontológicas y dialécticas, como brillantemente describe Monteci$\operatorname{nos}^{78}$. Sin embargo, aún no ha llegado un momento profundamente moderno que Hegel vio cumplido en su filosofía y en su concepción de absoluto: el reconocimiento del absoluto como sujeto, el reconocimiento de la autoconsciencia en el darse del devenir del mundo. Y es que es este momento moderno el que posibilitaría que ya no se tenga que hacer referencia a un objeto externo, a una dimensión ontológica superior que se escapa de nuestro mundo, sino que reconozcamos en el devenir de lo real, en el exponerse conciliado de las distintas figuras contradictorias que se dan en el proceso de darse de lo real aquella verdad que Hegel encontró en el conocimiento especulativo. Una dialéctica

76 GADAMER, H. G., La dialéctica de Hegel, op. cit., p. 33.

77 Ídem, y PLATÓN, Diálogos V. Parménides. Teeteto. Sofista. Político, Gredos, Madrid, 1988, p. 457. Para estos análisis, que hemos tomado del esencial trabajo de Gadamer La Dialéctica de Hegel y especialmente su primer capítulo, fueron esenciales los estudios de HEYDER, K. L. W., Kritische Darstellung der Aristotelischen und Hegelschen Dialektik, Erlangen, 1845.

78 MONTECINOS, S., "Conexiones metodológicas entre las filosofías de Platón y Hegel: la lectura platónica de la dialéctica hegeliana», op. cit., pp. 117 y ss. 
moderna, en definitiva, que tras romper los cascarones del pensamiento de su tiempo y de las antiguas dialécticas, se yergue hacia nuevos caminos.

\section{Conclusiones: los horizontes de una Ítaca}

¿Qué debe Hegel a Platón en el surgir de las primeras configuraciones de su pensamiento dialéctico? Sin lugar a duda, gran parte de la posibilidad de estos planteamientos. Sin la larga compañía que Hegel buscó en la filosofía platónica durante toda su juventud, hoy sería difícil imaginar el surgimiento de los planteamientos dialécticos que caracterizaron a la filosofía hegeliana. Sin embargo, como debemos notar en este final de esta última sección, Hegel no tomó a Platón como un mero modelo al que copiar, sino como un trampolín para ejercer una navegación que ya es propia de la Modernidad: su propio camino dialéctico.

Los horizontes abiertos tras este largo viaje de génesis y elaboración de la dialéctica hegeliana que recorrió con (y sobre) Platón son tan inmensos, quizá, como los horizontes del mundo que nació con su época. Y no solo hay que pensar en Marx y ese tono dialéctico que sigue resonando en El Capital (aunque algunos quieran dejar de oírlo). ¿Qué decir de Butler, y de las revoluciones de género que su teoría ha pensado, sin notar el elemento hegeliano que hay en su obra desde su misma tesis doctoral? ¿O de Taylor, y su respuesta comunitarista al pensamiento de Rawls? La profunda ruptura que, saltando sobre Platón, provocó Hegel y su comprensión procesual del exponerse de lo verdadero más allá de una verdad como adecuación digna de otros tiempos, se extiende por pasajes que aún merecen el nombre de un mañana, como los ecos platónicos extienden su sombra en estos tiempos tan alejados de la Antigua Atenas.

Sin embargo, pensar, seguir pensando y problematizando los orígenes y los senderos de estos pensamientos fundamentales de la historia de la filosofía sigue siendo fundamental para no limitar nuestras voces a una mera repetición de lo pasado. Porque quizá en la labor que construye nuevos mundos, los mejores herederos de Hegel no sean los que repitieron acríticamente su teoría ni los que la abandonaron sin pensarla, sino los que saltaron, sobre ella y frente a ella, hacia otra forma que nos permita vivir en el mundo. Eso fue exactamente lo que intentó Hegel frente a la filosofía platónica. Y no podemos asumir que este camino fuera fácil, ni filosófica ni humanamente, pero como decía el poeta, «allá donde reside el peligro, crece también lo que nos salva» ${ }^{79}$. 


\section{Bibliografía}

ADORNO, T. W., Notas sobre literatura, Obra completa. 11, Ediciones Akal, Madrid, 2003.

BARRIOS CASARES, M., «Hegel, una interpretación del platonismo», Anales del seminario de metafisica. Universidad Complutense, Madrid, 1995, pp. 125-147.

—_, «La incidencia de la imagen de Grecia en la obra temprana de Hölderlin», Contrastes: revista internacional de filosofia. XXII, n. ${ }^{\circ}$ 2, 2017, pp. 121-137.

CORTÉS, H. y LEYTE, A. (eds.), Cartas Fïlosóficas de Hölderlin, La Oficina, Madrid, 2020.

DUQUE, F., Historia de la filosofia moderna. La era de la crítica. Akal, Madrid, 1998.

DÜSING, K., Das Problem der Subjektivität in Hegels Logik. Systematische und entwicklungsgeschitliche Untersuchungen zum Prinzip des Idealismus und zur Dialektik, Bouvier, Bonn, 1976.

GADAMER, H. G., La dialéctica de Hegel. Ediciones Cátedra, Madrid, 2000.

HARRIS, H. S, Hegel's Development: Towards the Sunlight. Oxford, Oxford University Press, 1971.

HEGEL, G. W. F., La Relación del Escepticismo con la Filosofia, Biblioteca Nueva, Madrid, 2013.

—_ Fenomenología del Espiritu, Abada, Madrid, 2010.

—, Lecciones sobre Historia de la Filosofia II, Fondo de Cultura Económica, Ciudad de México, 2005.

—., «Fragmento de Tubinga», Revista de Filosofia, Editorial Complutense, Madrid, Época III, Vol. VII, 1994, pp. 139-176.

—_, La diferencia entre los sistemas filosóficos de Schelling y Fichte, Alianza Universidad, Madrid, 1989.

—- Historia de Jesús, Taurus, Madrid, 198.

—_, Escritos de Fuventud, Fondo de Cultura Económica, Ciudad de México, 1978.

HEIDEGGER, M., «Hegel y los griegos», Revista de Filosofia, 1966, Vol. 13 (1), 115-130.

—, Nietzsche (traducción por Juan Luis Vermal), Editorial Ariel, Madrid, 2013, pp. 624-682.

HEYDER, K. L. W., Kritische Darstellung der Aristotelischen und Hegelschen Dialektik. Erlangen, 1845.

HÖLDERLIN, F., Ensayos, Peralta, Madrid, 1976.

— , F., Poemas, DeBolsillo, Madrid, 2014.

HYPPOLITE, J., Génesis y estructura de la Fenomenología del Espiritu de Hegel, Ediciones Península, Madrid, 1974.

SOLÉ, M. J., El ocaso de la Ilustración: La polémica del spinozismo, Universidad Nacional de Quilmes, Bernal, 2012.

KANT, I., Crítica de la Razón Pura. Taurus, Barcelona, 2013.

—, «Qué es la Ilustración», Foro de la Educación. 11, 2009, pp. 249-254.

MARTÍNEZ MARZOA, F., De Kant a Hölderlin, La Oficina, Madrid, 2018.

MONTECINOS FABIO, S., «Máscaras del escepticismo en la filosofia hegeliana», Estudios de Filosofia, Universidad de Antioquía, Antioquía, n. ${ }^{\circ}$ 60, 2019, pp. 110-140.

—_, La asunción de la reflexión finita en la filosofia de G. W. F. Hegel, UAM, Madrid, 2015.

—_, «Conexiones metodológicas entre las filosofías de Platón y Hegel: la lectura platónica de la dialéctica hegeliana». Bajo Palabra, UAM, Madrid, época II, n. ${ }^{\circ}$ 4, 2009, pp. 104-127.

PLATÓN, Parménides, Alianza Editorial, Madrid, 2013. 
—_, El Banquete, Alianza Editorial: Madrid, 1999.

—_, Diálogos III. Fedón. Banquete. Fedro, Gredos, Madrid, 1989.

—, Diálogos V. Parménides. Teeteto. Sofista. Político, Gredos, Madrid, 1988.

SURBER, J. O., «Hegel's Plato: A new departure», en KIM, A. (ed.), Brill's Companion to German Platonism, Brill, Leiden, 2019.

VÉLEZ, M., «Parataxis poética como pharmakon para la transgresión filosófica: Hegel, Hölderlin y Adorno», en CARRASCO CONDE, A., MACOR, L. A. y ROCGO LOZANO, V. (eds.), Hegel y Hölderlin: una amistad estelar, Círculo de Bellas Artes, Madrid, 2021.

VIELLARD-BARON, J.-L., Platonisme et interprétation de Platon à l'époque moderne, Vrin, Paris, 1998. 